\title{
Heat Transfer Enhancement from Microprocessor
}

\author{
M. Sivasubramnanian, K. D. Jaganathan,
}

\begin{abstract}
Experiments were conducted to investigate the cooling of processor to increase the thermal performance by employing a mini channel instead of conventional heat sinks. Now a day's aluminium fin with fans is used for cooling the processor. Constant speed of the fans is found to be not enough to remove the heat generated by the processor. The experimental investigations were carried out in the channels with the hydraulic diameter of about $1.5 \times 10^{-3} \mathrm{~m}$ for the Reynolds number varying from 80 to 1150. The water is allowed to pass through the channel by virtue of which heat is rejected from the processor. The influence of Reynolds number on heat transfer enhancement from the microprocessor is discussed in details. Comparison between heat transfer by air and by water is presented. From the experiment it is disclosed that further increase in heat transfer was observed when compared to air.
\end{abstract}

Keywords : Mini channel, liquid cooling, Electronic cooling, Reynolds number.

\section{INTRODUCTION}

I this decade, there is a rapid development in desktop computers but the heat generated from the processor still invites efficient cooling methods to maintain the processor temperature at an optimum level below 1000C. Hence the evolving an efficient cooling techniques for the micro channels becomes very important task. The liquid cooling with mini channel on the processor is quite efficient method for cooling the processor by the result obtained. Unless the heat is removed on the processor, the temperature of the device will keep on increasing which leads to decrease in efficiency, and finally it damage entire system unit. Hence keeping the temperature with in the allowable limit has been a great challenge.

Joule's law of heat dissipation follows the equation I2R. I is current and $\mathrm{R}$ is resistance, hence it is obvious that as compactness increases internal heat production improves. High heat flux removal mechanism is needed for efficient cooling system. The dimensions of electronic components are at micro/mini scale, it is mandatory to use a proper cooling system in the same scale. In this experimental study the mini channel is used in the process to cool down the processor with the fluid flow. The Deionized water is a fluid

Revised Manuscript Received on December 29, 2019.

M. Sivasubramanian*, Department of Automobile Engineering, School of Automotive and Mechanical Engineering, Kalasalingam Academy of Research and Education, Tamilnadu - India. Email: m.sivasubramanian@klu.ac.in

K. D. Jaganathan, Assistant Professor, Department of Mechanical Engineering, SACS MAVMM Engineering college, Madurai, Tamil Nadu, India. Email: jaganathan1978@gmail.com which is used in the process. The result obtained shows the temperature variation in existing process with liquid flow in mini channel. According to [1] varying the hydraulic diameter from micro to mini scale configurations, at lower pressure drop, significant heat transfer coefficient may be obtained at relatively high for specific application. The flow of fluid through the micro and mini channel was efficient for small scale cooling and it is one of the most effective methods. Mousa M. Mohamed [2] experimented the air cooling of mini channel heat sink in an electronic device under steady state with air flow rates range of $0.002-0.0005 \mathrm{~m} 3 / \mathrm{s}$, for various heating capacity from 80-200W, these experiment carried with two channels one as rectangle and another is triangle. The result disclosed that increase in mass flow rate and base temperature the heat transfer improved. Compared to triangular channels rectangular channels have better thermal performance. G.Hetsroni [3] reported that temperature distribution relay on the design, material of the module and type of working fluid. Increasing the pressure head and making the coolant to move at higher rate were the factor which controls the rise in temperature of the channel in heat sink design with a single phase fluid.

M.Mousa Mohamed [4] investigated the characteristics of a uniform square modulus array for electronic device heat sink on air cooling. The results exposes that there was a significant increase in heat transfer coefficient with increase in modulus array base temperature. Increase in air flow velocity significantly affects the increment in heat transfer rate between the modulus surface and flowing air.

$\mathrm{Xu}$ B., et al. [5] presented investigation by conducting experiments to study the flow friction for liquid flow in micro channels. End results depict that relationship between the Reynolds number and friction factor for various specimens. The measurement of heat transfer characteristics of gas flow in a fine channel heat exchangers device was investigated by Peiyi $\mathrm{Wu}$ and W.A little [6]. The result obtained illustrates the flow resistance characteristics for channels used in micro miniature refrigerator and three correlations were suggested to represent the three different flow zones. Conjugate situation in a flow through the mini channel was reported by Manoj Rao and Sameer Khandekar [7]. Results reported shows for developing flow shows very high influence on heat transfer rate in the entrance regions.

Overheating of the CPU will result in rebooting of the system and affects the performance of the processor and leads to failure of the system. For better performance of the system and to maintain the temperature of the system at optimum level below $100^{\circ} \mathrm{C}$. The generation of heat in the processor may reduce its 
reliability and life span of the device.

From this study it was identified that the heat flux ranging from $330 \mathrm{w} / \mathrm{cm}^{2}$ to $520 \mathrm{w} / \mathrm{cm}^{2}$ generated from a single chip. Hence it is necessary to identify an efficient cooling system to address the issues related to overheating and this is the most vital problems in designing electronic components. According to Keyur Thakkar [1], geometry, surface texture of channel, mass flow rate, specific heat of fluid and fluid flow were the influencing parameters. G.Hetsroni, et al [3], disclosed the drawback of a micro channel heat sink was high temperature rise in heat sink wall compared to conventional heat sinks.

\section{EXPERIMENTAL SETUP AND PROCEDURE}

The fabricated experimental setup is displayed in figure 1. In an aluminium mini channel of $40 \mathrm{~mm} \times 1 \mathrm{~mm} \times 3 \mathrm{~mm}$, with a test section area of $3 \mathrm{~mm}^{2}$ with an hydraulic diameter of $\mathrm{D}_{\mathrm{h}}=$ $1.5 \times 10^{-3} \mathrm{~m}$ was used for the experimentation. The reservoir provides a constant flow to the channel with help of DC pump and the flow is measured by amount of water collected. The working fluid required for the experimentation was stored in a main tank of capacity 5 liters. Mineral water was poured to the reservoir using the $100 \mathrm{ml}$ beaker for a constant level of reservoir. To maintain the water flow constant through the mini channel, a pressure regulating valve was provided. In test section Type $\mathrm{K}$ thermocouple was installed in a mini channel with a depth of $30 \mathrm{~mm}$ on the four sides of the aluminium mini channel. The channel is closed by the plexi glass of $10 \mathrm{~mm}$ thickness was used to provide the system from the leakage and it was well separated from environment to reduce the losses on the other directions. The mini channel is mounted over the microprocessor. Type $\mathrm{K}$ thermocouples were provided to acquire the surface temperature of the mini channel, entry and exit temperature of the water. Control panel was used to provide each temperature by operating 12 node switch.

Working fluid as water was preferred with kinematic viscosity of $\mathrm{U}=8.351 \times 10-7 \mathrm{~m}^{2} / \mathrm{s}$ at room temperature $30^{\circ} \mathrm{C}$. Once the steady flow was achieved, time taken to collect the $100 \mathrm{~g}$ of water.

To ensure the Reynolds number of the flow, the same procedure was repeated with different flow rate was used to calculate the Reynolds number using the following expression Eq. (1).

$R e=\frac{\tilde{m} D_{h}}{A_{s} \mu}$

Varying the flow regulating valve desired water flow rate was given to the mini channel. Steady state was reached after twenty minutes and it was ensured by taking readings in every five minutes of interval. Once the steady state reached the temperature of mini channel (T1-T8), temperature of the water at the inlet (T9) at the outlet (T10) and the ambient temperature (T11) were noted and tabulated. The temperature difference to the mini channel was calculated as reported using Eq. (2)

$\Delta T_{\operatorname{lm}}=\frac{\left(T_{s}-T_{0}\right)-\left(T_{s}-T_{i}\right)}{\ln \left[\left(T_{s}-T_{n}\right) /\left(T_{g}-T_{i}\right)\right]}$

Where, Ts is the surface temperature of the mini channel, To is the outlet temperature of the water and $\mathrm{Ti}$ is the inlet temperature of the water. Eq. (3) was used to obtain the heat transfer coefficient.

$$
h=\frac{Q_{c}}{A_{c}} \times \Delta T_{l m}
$$

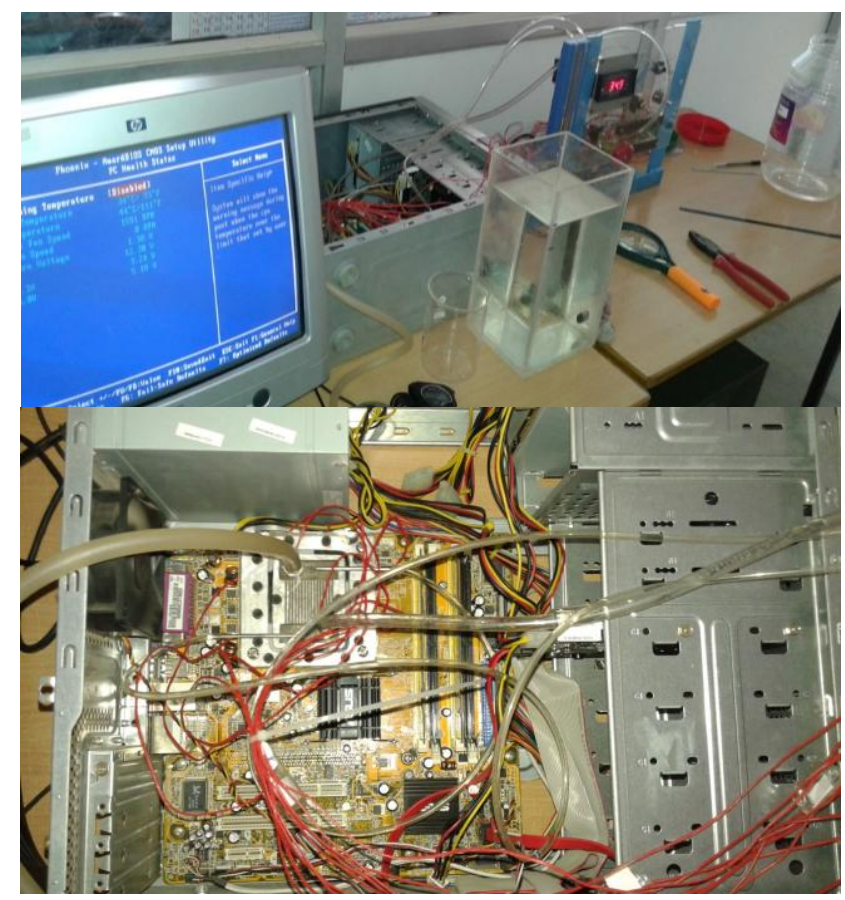

Figure 1. Experimental Setup

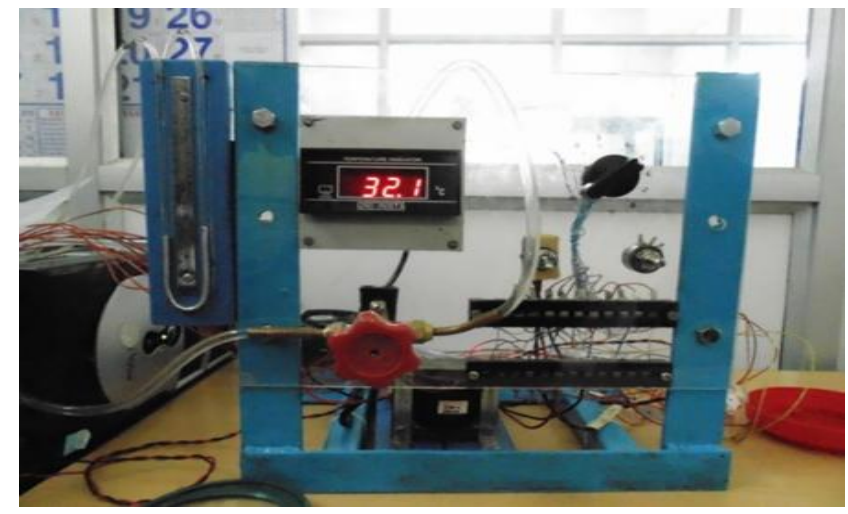

Figure 2. Panel setup

The Nusselt number was evaluated using the expression. $N u=\frac{h D_{h}}{K}$

Where, $\mathrm{h}$ is the heat transfer coefficient, $\mathrm{k}$ is the thermal conductivity of the water.

\section{RESULTS AND DISCUSSION}

In this experimental study the rectangular mini channel is used for the heat transfer from the processor. According to [3] the rectangular mini channel is more efficient than triangular mini channel and hence rectangular mini channel is used in this experimental study. $\mathrm{Re}$ and $\mathrm{Nu}$ is calculated to compare the heat transfer rate of air and water by increasing the heat transfer rate, Reynolds number is also increases. If $\operatorname{Re}<2300$ is flow is laminar [8] and in this present experimental study Re obtained is lesser than 2300 and hence the flow is laminar flow and the hydraulic diameter of the mini channel is $1.5 \times 10^{-3} \mathrm{~m}$. 


\section{A. Working fluid - Water}

The increasing of Reynolds number increases the mass flow rate, because the Reynolds number is directly proportionate to the mass flow rate figure 3 . Figure 4 shows the relationship between the Reynolds number and heat transfer coefficient. It is a fact that the increasing of Heat transfer coefficient $(K)$ is based on the increase of Reynolds number.

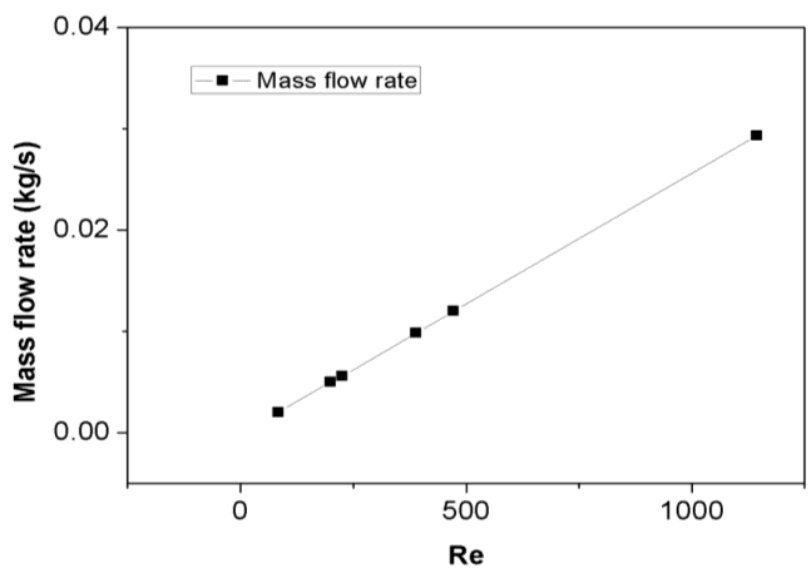

Figure 3. Relationship between Re vs. im

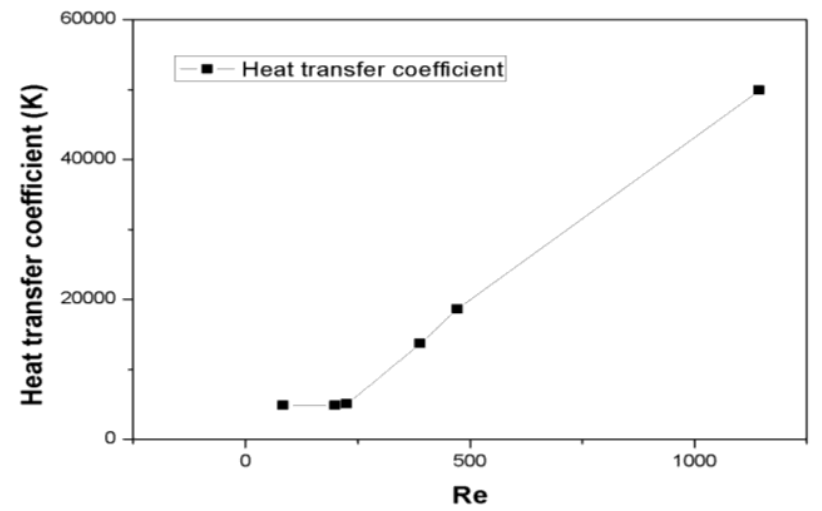

Figure 4. Relationship between Re vs. h

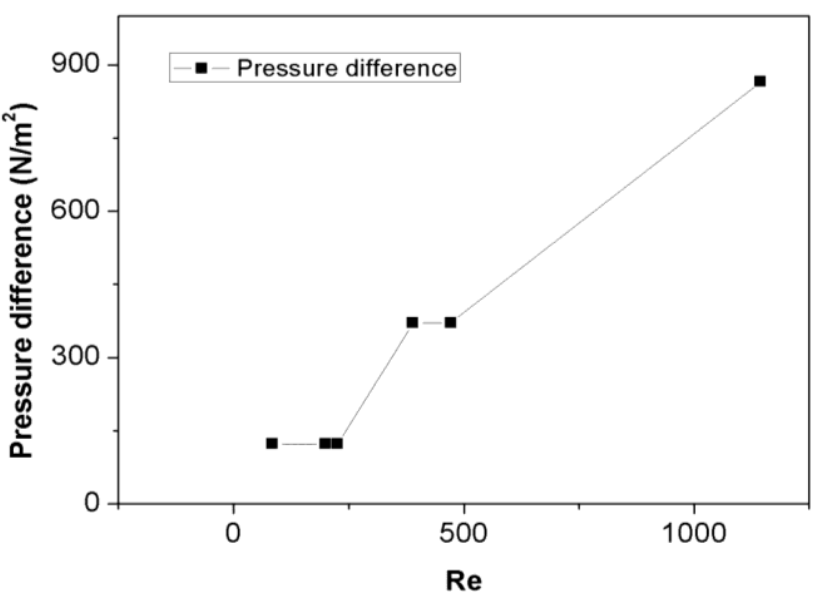

Figure 5. Relationship between $\operatorname{Re}$ vs. $\Delta p$

Figure 5 depicts that the relationship between the Reynolds number and the pressure drop. If Reynolds number increases, the pressure drop is also increasing. This is due to the fact that the increase in flow increases the pressure drop in a linear manner by overwhelming the Inertia force. Figure 6 discloses the relation between the Reynolds number and
Nusselt number. It is found that increasing trend is obtained as stated in [4].

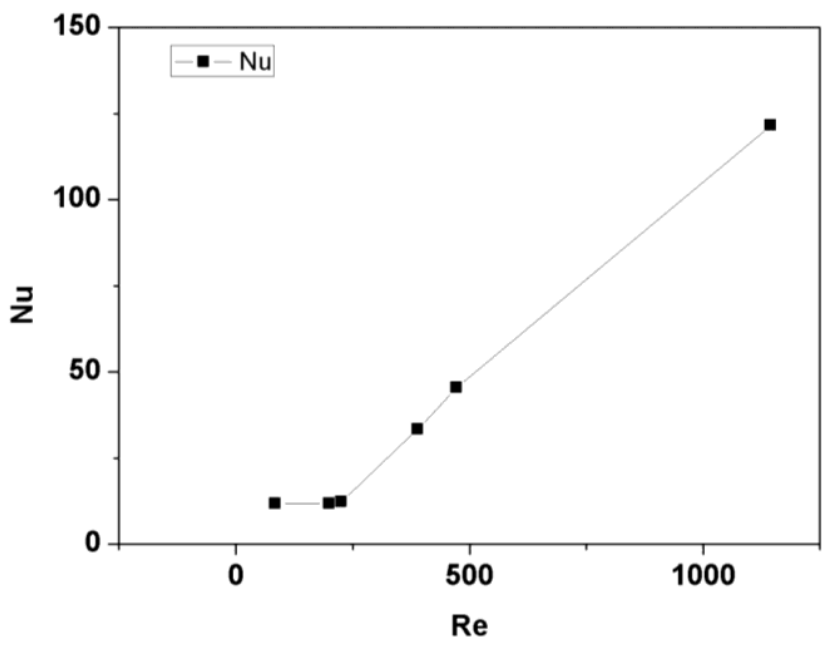

Figure 6. Relationship between Re vs. Nu

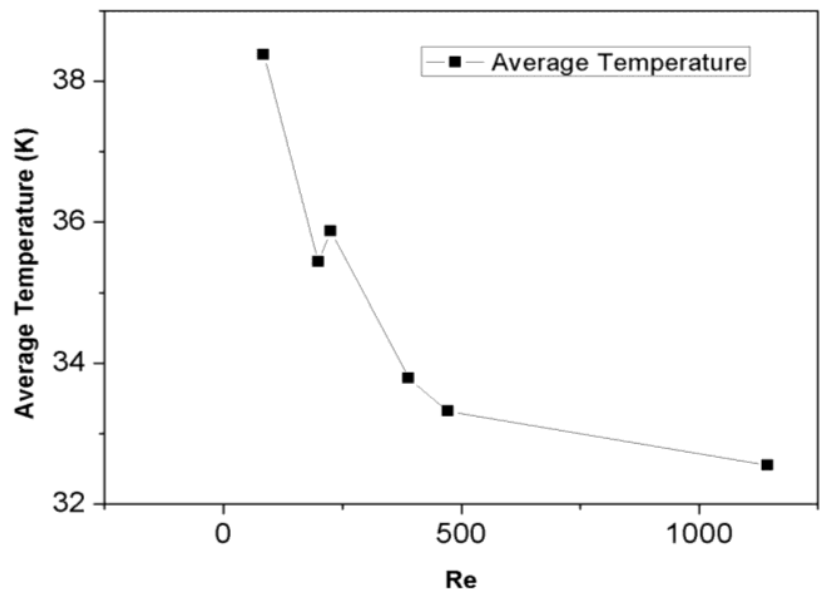

Figure 7. Relationship between Re vs. Tavg.

Due to uncertainty in the experiment there is a variation in the temperature and fig 7 shows the relationship between $\mathrm{Re}$ and average temperature.

\section{B. Working fluid - Air}

The operating temperature of the system is calculated in existing process at different working condition. By this experimental study the operating temperature increases at different working condition. Initially the system is turned on and the temperature during booting time is observed. The thermocouple is placed at five different places in the aluminium fins and the temperature at various areas is observed and displayed in the temperature indicator. The temperature at word processing and gaming is also observed. And as a result temperature at gaming condition is greater than any other working condition. The velocity of the chassis fan is measured by using anemometer. The velocity of chassis fan is measured at the four different places and the average velocity is about $0.9 \mathrm{~m} / \mathrm{s}$. The accuracy of anemometer is $\pm 3 \%$ and its range is $0 \sim 45 \mathrm{~m} / \mathrm{s}$. 


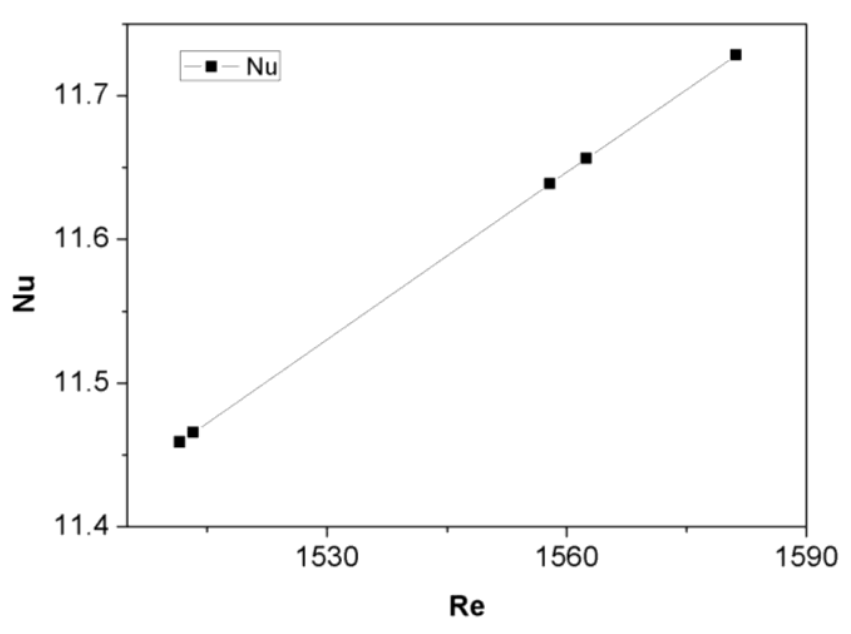

Figure 8. Relationship between Re vs. $\mathrm{Nu}$

Figure 8 represents that the relation between the Reynolds number and Nusselt number when air is used as a working fluid. This also follows a similar trend as like water as a working fluid. Figure 9 describes the performance of the microprocessor during the various working conditions like booting of the system, idle condition, normal working conditions and gaming conditions. The temperature rise is observed in gaming condition when compared to all other working conditions. From this it alarms that the usage of the microprocessor is more when compared to other situations. Hence the generation of excess heat must be exhausted to improve the performance of the processor.

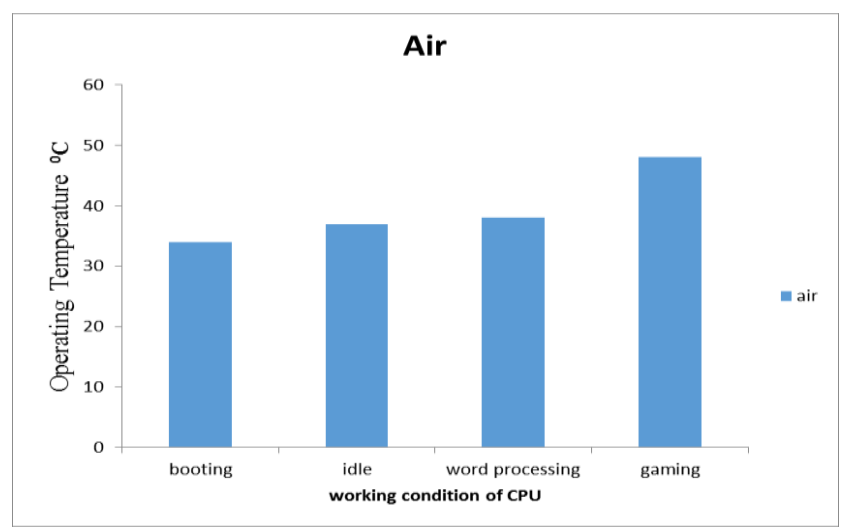

Figure 9. Performance of CPU

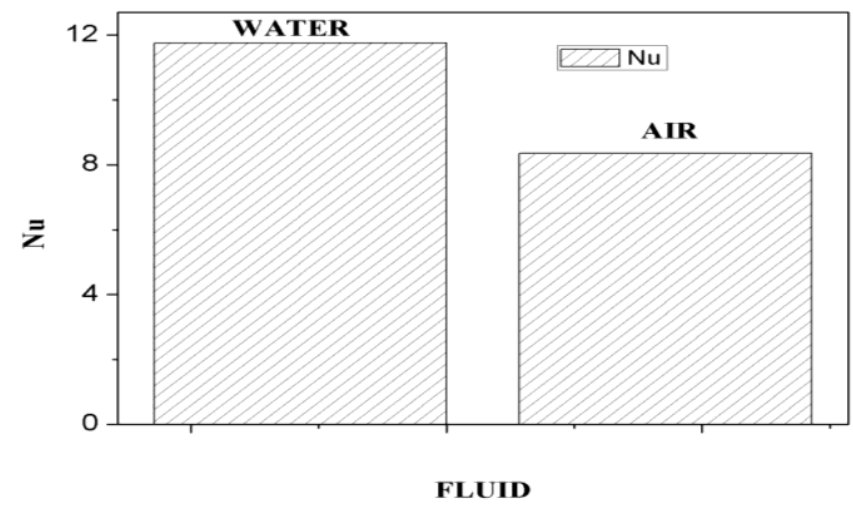

Figure 10. Comparison performance of the processor

Figure 10 describes that the comparison of performance of the microprocessor when water and air used as working fluid. Comparing the Nusselt number for air and water on idle condition, it is proposed that Nusselt number for water is greater than the Nusselt number for air and the efficiency of water is $40.85 \%$ greater than air and hence it is proposed that water is efficient cooling method over air.

\section{CONCLUSIONS}

The experimental investigation was carried out to compare air and water and the results shows that the efficiency of water is greater than the air. The investigation of heat transfer enhancement from microprocessor through a mini channel array was experimentally studied. Re was varied from 80 to 1150 under the steady state and state flow achieved at different flow rate. The results were summarized as the following: Very high heat transfer coefficients were observed at entrance regions on developing flow situations. $40.85 \%$ increase in heat transfer was observed when compared to conventional heat sinks which uses air as working fluid. From this study it is suggested that conventional heat sinks may be replaced by the mini channels with water as working fluid for the better performance of the processor.

\section{REFERENCES}

1. Keyur Thakkar. "Thermal and hydraulic characteristics of single phase

2. Flow in mini channel for electronic cooling" Published on international journal of innovative research in science, engineering and technology vol. 3, 2014 issue 2,ISSN 2319-8753.

3. Mousa M.Mohamed*,Mostafa A.Abd El-Baky. Mousa "Air cooling of mini channel heat sink in Electronic devices" Published on journal of electronics cooling and thermal control, 2013, pp. 49-57.

4. G.Hetsroni, et al "A uniform temperature heat sink for cooling of electronic devices" published on international journal of heat and mass transfer 2002 pp.3275-3286.

5. Mousa M.Mohamed "Air cooling characteristics of a uniform square modules array for electronic device heat sink" published on applied thermal engineering 2006 pp. 486-493.

6. Xu B., Ooi K.T., Wong N.T, "Experimental investigation of flow friction for liquid flow in micro channels" published on int. comm. Heat mass transfer, vol no 8, 2000 pp. 1165-1176.

7. Peiyi $\mathrm{Wu}$ and W.A.little "Measurement of heat transfer characteristics of gas flow in fine channel heat exchangers used for micro miniature refrigerators" published on 0011-2275/84/008415-06 \$03.00 c 194 butterworth \& co (publishers) ltd CRYOGENIUS, 1984 pp. 415-420.

8. Manoj Rao and Samer Khandekar "Simultaneously developing flows under conjugated conditions in a mini channel array liquid crystal thermography and computational simulations" published on heat transfer engineering, 30(9)2009, pp.751-761.

9. C P Kodhandaraman and S Subramanyan "Heat and Mass Transfer Data Book" New age international (P) limited, publishers.

\section{AUTHORS PROFILE}

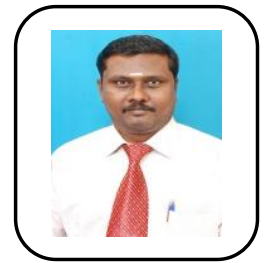

Sivasubramanian. M obtained his Bachelor's Degree in 1999 from Madurai Kamaraj University. Further he completed his Master's degree in Production Engineering from Anna University, India in 2005. He was awarded with Ph.D. degree in Faculty of Mechanical Engineering in the year 2015. During his research career he has published 14 International journals and participated and published many International conferences papers. He actively involved in inventing things related to automobile and mechanical engineering and as an outcome of this, he has registered 19 patents in INDIA. One of his inventions is eco-friendly hybrid electric car with self-electrical charging for which he received a fund of One lakh Rupees from Innovation and Entrepreneurship Development Centre, National Science \& Technology Entrepreneurship Development Board (NSTEDB) Department of Science \& Technology Department of Science and Technology. 
His research interest includes fluid dynamics, Conjugate heat transfer, experimental heat transfer and flow separation using CFD techniques. $\mathrm{He}$ started his career as teaching faculty from 1999 and currently working as an Associate Professor in the Department of Automobile Engineering, Kalasalingam Academy of Research and Education, India. He holds life membership in Life member in Indian Society for Heat and Mass Transfer (ISHMT), India and Life member in Indian Society for Technical Education (ISTE), India.

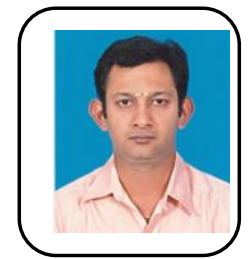

Jaganathan. K.D obtained his Bachelor's Degree in 1999 from Madurai Kamaraj University. Furthe completed his Master's degree in Computer Integrated Manufacturing from Visvesvaraya Technological University, Belagavi, India in 2001. His research interest includes fluid dynamics, experimental heat transfer and flow separation using CFD techniques. Currently working on the above said research area and published an international journal and communicated three international journals. He started his career as teaching faculty from 2004 and currently working as Assistant Professor in the Department of Mechanical Engineering, SACS MAVMM Engineering College, Kidaripatti, Madurai, India. He holds life membership in Indian Society for Technical Education (ISTE), India. 